\title{
ASSESSORIA DE IMPRENSA EM INSTITUIÇÕES RELIGIOSAS: mecanismos profissionais versus proselitismo ${ }^{1}$
}

\author{
PRESS OFFICE IN RELIGIOUS INSTITUTIONS: \\ Professionals mechanisms versus proselytizing
}

EDUARDO TEIXEIRA ${ }^{2}$

Resumo: Ao agir por meio da assessoria de imprensa, as instituições religiosas constroem alicerces pela comunicação profissional, planejada e estratégica e, agregam valor aos públicos ao mostrar a sua imagem e suas ações e também ao discutir projetos. A incorporação das ferramentas comunicacionais disponíveis na assessoria de imprensa é um dos mecanismos que torna possível ampliar o vínculo e a participação social das instituições religiosas através da mídia, fortalecendo a identidade da instituição e fundamentando os relacionamentos com a comunidade na qual ela está inserida. Dessa maneira, as ações eclesiais não ficam atreladas apenas ao proselitismo, que em muitos casos atinge o patamar de "guerra santa" midiatizada nos veículos de comunicação brasileiros.

Palavras-chave: comunicação; assessoria de imprensa; instituição religiosa; mecanismos profissionais; proselitismo.

Abstract: Proceed through a press office, the religious institutions builds foundations for professional communication, planned and strategic and add value to the public to exhibit their image and their actions and also to discuss projects. The incorporation of

\footnotetext{
${ }^{1}$ Artigo apresentado no IV Seminário de Pesquisas em Mídia e Cotidiano: Discursos Midiáticos e Prática Sociais, realizado entre os dias 26 e 28 de setembro de 2012 na Universidade Federal Fluminense.

2 Pós-graduado em Marketing pela FAE-Business School (Curitiba,PR). Graduado em Comunicação Social, habilitação em Jornalismo pela Universidade Tuiuti do Paraná (UTP - Curitiba, PR) e Bacharel em Teologia pelo Centro Universitário Adventista de São Paulo (UNASP - Engenheiro Coelho, SP). Atualmente exerce a função de Assessor de Comunicação na Igreja Adventista do Sétimo Dia (Regional RJ, MG e ES). eduardo.teixeira@adventistas.org.br
} 
communication tools in the press office available is a mechanism that makes it possible to extend the bond and social participation of religious institutions through the media, to increase the identity of the institution and basing relationships with the community in which it is embedded. Thus, the ecclesial actions are not only linked to proselytizing, which often reaches the level of "holy war" in Brazilian media mediatized.

Keywords: communication; press office; religious institutions; professional mechanisms; proselytizing.

O número das organizações sem fins lucrativos cresce constantemente e elas têm ampliado e aperfeiçoado as atuações na sociedade e consequentemente, a sua comunicação frente aos mais variados públicos. Esse crescimento proporciona a visibilidade de novas parcerias entre os diferentes setores em nosso país, mas não significa que exista excelência em todos os âmbitos ou que não haja espaço para melhorias e a adoção de novos papéis transformadores ou renovadores nos espaços públicos ou em ações focadas a determinados grupos, maioritários ou não, inseridos no Brasil afora.

Com o primeiro setor constituído pelo Poder Público, o segundo pelas empresas privadas e o terceiro pelas organizações civis, que inclui entidades sociais, igrejas, partidos políticos (OLIVEIRA, 2009, p. 471), os brasileiros têm visto crescer o número de interações entre os setores e reconhecem e legitimam cada setor no papel coletivo que desempenham (SALVATORE, 2004, p. 24).

As organizações, sejam do segundo ou do terceiro setor, ganharam mais destaques quando atentaram ao contexto sociocultural mais amplo que determina suas atividades e relacionamentos com esse ambiente (ASHLEY, 2007, p. 9). Tanto que cada vez mais, há atuações específicas nos mais variados nichos de mercados ou de assistencialismos.

E toda a movimentação que permitiu ampliar as ações organizacionais e mantém o ritmo acelerado nesse aspecto está voltada para a comunicação que serviu de ferramenta entre organização e sociedade, permitindo um amadurecimento das relações. Justamente por isso, “a comunicação se formou como o insumo estratégico, que uma 
empresa ou entidade lança mão para fidelizar, sensibilizar e interagir” (BUENO, 2003, p. 33).

As práticas comunicacionais deixaram seu nível tático e intuitivo e a comunicação alcançou uma visão profissional realizada de maneira estratégica, ligada ao negócio das organizações como um todo (KUNSCH, 2009, p. 33). Afinal, é a informação que permite o encontro de interesses (ENRÍQUEZ, 2001, p. 11) entre a organização e a comunidade onde ela está inserida, o que auxilia nos feedbacks e nas adaptações necessárias a toda e qualquer ação organizacional.

As transformações vistas no cenário brasileiro em relação à atuação das corporações evidenciam-se pela busca de uma cultura de responsabilidade social (ASHLEY, 2007, p. 16). E como as instituições se orientam a servir a comunidade (ENRÍQUEZ, 2001, p. 08) não poderia haver distanciamento dos setores secundários e terciários para realizar trabalhos socialmente responsáveis, em um tempo em que essa questão anda ligada intrinsicamente com os produtos e com os serviços.

Atualmente, a comunicação também rende os seus esforços para estar associada ao exercício da cidadania, à gestão de responsabilidade social, ao respeito à diversidade e à valorização profissional e pessoal (BUENO, 2009, p. 384). Nos demais itens também se espera das organizações atitudes e atividades que valorizem os aspectos éticos e morais dos públicos/stakeholders envolvidos, os quais valorizem e priorizem os Direitos Humanos Universais, o respeito ao meio ambiente, as ações sustentáveis e um maior envolvimento na comunidade em que rodeia a organização (ASHLEY, 2007, p. 07).

As empresas do segundo setor trabalham com a comunidade e logicamente necessitam do lucro para sobreviver e até mesmo ampliar as interações com os seus públicos. Já as organizações sem fins lucrativos, inseridas no terceiro setor, precisam, ainda mais, fazer a diferença na sociedade e nos indivíduos, pois elas existem para isso e sua missão está voltada a esse aspecto (DRUCKER, 2006, p. 47). Sobretudo, as igrejas pastorais precisam fixar metas de desempenho específicas para cada grupo que pretendem alcançar, ligadas ao serviço às pessoas (IDEM, IBIDEM, p. 8). 


\section{míDiA

E é a comunicação que pode ajudar no posicionamento das organizações do terceiro setor (VOLTOLINI, 2004, p. 165), pois por meio dela há o diálogo entre organização-comunidade. Esse posicionamento não se refere ao diferencial competitivo, mas está voltado nesse momento para a interação entre os diversos públicos e setores. Ao mencionar públicos diferentes a igreja é lembrada por Kotler (apud. DRUCKER, 2006, p. 58) como uma instituição que deve ser muito diversificada e que precisa falar por diferentes líderes e laicos para os diferentes públicos que procura atender.

Com a evolução dos meios de comunicação e da própria rotina comunicacional, agora estratégica, a comunicação passa a ser mais efetiva por meio da multiplicação dos canais (BUENO, 2003, p. 28). Por isso, a atuação da assessoria de imprensa traz facilidades para as instituições religiosas que podem de maneira séria e profissional ampliar o diálogo com a sociedade com novas ferramentas.

Em qualquer instituição a política informativa permite atingir mais eficazmente os seus propósitos (ENRÍQUEZ, 2001, p. 175) e assim, o espaço eclesial precisa se alinhar cada vez mais com o macro-ambiente sociocultural que o envolve para que haja mais diálogo e harmonização com o mundo externo quanto à finalidade de ações e projetos. E não basta apenas falar, em muitas vezes é necessário que as instituições religiosas ouçam as expectativas dos públicos, os seus interesses e os desejos da comunidade e os incorpore ao seu modo de atuar (VOLTOLINI, 2004, p. 164). É uma transformação de mão dupla, de fala, escuta e adaptações. Realizar esses diálogos é privilégio das organizações, porque “a convivência com tais interações não é afirmação de autoridade, nem de distanciamento e sim de aproximação, transparência e relação saudável entre os públicos de interesse” (BUENO, 2009, p. 384).

A ponte entre os três setores é feita pela comunicação e ela abre espaço para um relacionamento mais aprofundado entre eles, o que possibilita uma política pública capaz de resolver ou amenizar os problemas sociais existentes (OLIVEIRA, 2009, p. 482). Dentro dessa perspectiva, as instituições religiosas têm muito a oferecer à sociedade, mas em diversos momentos em vez de divulgar de maneira profissional suas ações e a oferta de parcerias por meio das assessorias de imprensa, se digladiam em horário quase nobre na 


\section{míDiA \\ eC DiAno}

\section{PPGMC}

televisão e em outros meios de comunicação; demonstrando as fragilidades comunicativas no escopo eclesial. Ao invés de construir pontes e auxiliar a sociedade, o uso proselitista agressivo dos meios de comunicação, acabam por levantar muros na esfera pública; distorcendo a comunicação e a existência das instituições religiosas.

\section{Assessoria de Imprensa}

A assessoria de imprensa acompanhou as mudanças comunicacionais no Brasil e no exterior e permanece como ferramenta profissional que permite a administração do fluxo de informação, seja em instituições privadas ou públicas, que media o relacionamento entre fontes para os veículos de comunicação e vice-versa e também é responsável pela edição de materiais impressos e eletrônicos para os públicos de interesse (DUARTE, 2011, p. 68; FENAJ, 2007; FERRARETTO e KOPPLIN, 2001, p. 13). E mais, agora ela

estabelece pontes entre as diversas vertentes da entidade, sintetiza e consolida oportunidades de divulgação, que atendem a objetivos estratégicos da organização. Ela se estrutura valendo-se de banco de dados inteligentes (de veículos, editorias e colunas; de profissionais de imprensa, ou seja, repórteres especializados, colunistas, etc.) para planejar, de maneira sistemática, a exposição de produtos, serviços, marcas e a própria missão/visão da organização (BUENO, 2003, p. 88).

E como sempre, desde o seu surgimento, a assessoria de imprensa não trabalha sozinha, faz parte de uma comunicação integrada que funde relações públicas, comunicação digital, propaganda e publicidade, patrocínio/parcerias, editoração, comunicação interna, marketing, etc. (DUARTE, 2011, p. 68). E, todas as atividades do assessor estão em maior ou em menor grau voltadas para a formação da opinião pública (FERRARETTO e KOPPLIN 2001, p. 24).

Portanto, o profissional de assessoria, assim como toda a comunicação que deixou seu aspecto de investimento secundário, passou a ser prioritário em organizações, dos diferentes setores da sociedade, e atua como gestor. Afinal, os limites técnicos foram ultrapassados até chegarem ao ponto de interação do processo de tomadas de decisões 


\title{
míDiA \\ eClo DiAno
}

(BUENO, 2003, p. 86). Dessa maneira, o assessor deve transitar por todos os setores das organizações e conhecer a sua história e os seus planejamentos para atuar estrategicamente nas definições a serem realizadas; garantindo a coerência entre o passado, o presente e o futuro organizacional. Justamente por possuir essas responsabilidades o apoio ao assessorado também precisa ser constante para o aperfeiçoamento, e por isso é necessário

\begin{abstract}
capacitar fontes e porta-vozes para compreender a dinâmica da imprensa e interagir com jornalistas. Assim, cria-se ou fortalece uma cultura de comunicação. Isso amplia a atuação e a boa visibilidade quando solicitados e minimizam os riscos e enfrentam crises mais preparados. Essa preparação ajuda na transmissão à sociedade quanto às precisões informativas e garante uma correta percepção (DUARTE e FARIA, 2011, p. 356).
\end{abstract}

Esse apoio ao assessorado é serviço diário em uma boa assessoria, pois ela e suas fontes devem estar "munidas com informações relevantes que serão levantadas pelos jornalistas quando solicitados” (BUENO, 2003 p. 79) e essa é a razão pela qual o relacionamento entre assessor e assessorado se estabelece num nível extremamente profissional, sempre respeitando à capacidade e áreas de conhecimento de cada um (FERRARETTO e KOPPLIN, 2001, p. 50).

A garantia da correta percepção da organização perante os públicos, via assessor e assessorado, passa a ser um sinal do profissionalismo existente e resultado do trabalho técnico-estratégico. Para tanto, é fundamental que o assessor realize o seu trabalho com postura ética ao que diz respeito principalmente no relacionamento com a mídia, de maneira a usar isso como instrumento importante de inteligência, para conseguir não só usar a sua capacidade de suprir os jornalistas com informações relevantes, mas também estabelecer parcerias duradouras (BUENO, 2003, p. 87).

Mesmo com tantas adaptações e melhorias o papel básico do assessor não pode ser esquecido e as ampliações nos serviços também não devem ser menosprezadas.

O assessor de imprensa tem que manter a competência da atividade original e ampliar os conhecimentos, responsabilidades e possibilidades em um ambiente comunicacional volátil. Independentemente da abrangência de sua atuação permanece o senso de ampliação de transparência, qualificação dos 


\section{PPGMC}

relacionamentos, agilização dos fluxos informativos; melhorando assim a comunicação tanto para a sociedade quanto para a organização (DUARTE, 2011, p. 71).

Por isso, o assessor continua a ser o profissional que constrói e amplia a ponte comunicativa entre a organização e a comunidade por meio de ferramentas da assessoria; quer sejam elas releases, entrevistas, materiais impressos ou eletrônicos ou parcerias. É função do assessor colaborar para derribar os muros da incompreensão e da incoerência e aperfeiçoar o diálogo, as atividades e os planejamentos das organizações, auxiliando assim, a relevância das instituições no ambiente em que se encontram inseridas.

\section{Cultura, Imagem e Identidade}

As trocas de recursos e informações entre os membros da organização e da sociedade fazem com que o ambiente organizacional tenha características de um movimento de contínua reinterpretação da realidade (ALMEIDA, 2008, p. 34). O canal de assimilação e adaptação é a comunicação que tem na assessoria de imprensa um instrumento profissional capaz de conduzir e formar os processos comunicacionais que as organizações balizam em relação aos inúmeros públicos (NASSAR, 2008, p. 247).

Por isso, a relação entre quem é a organização e a percepção de seus grupos de relacionamentos significam a construção de sentidos para que interna e externamente os resultados sejam consistentes com a cultura, os valores, as ações e as premissas institucionais (ALMEIDA, 2008, p. 44).

Quando se fala em cultura é preciso considerar que ela é “um produto do processo histórico, o que significa construção e não há como visualizar construção sem comunicação” (MARCHIORI, 2008, p. 85). E em relação à sua formação, ela se dá através

da atuação dos grupos e ela acaba por fomentar a personalidade da organização. Os grupos relacionam-se, desenvolvendo formas de ser e agir que vão sendo incorporadas por eles. A comunicação é fundamental nesse processo, pois a cultura se forma a partir do momento em que as pessoas se relacionam. Portanto, a comunicação forma a cultura organizacional por meio da construção de significados (IDEM, IBIDEM, p. 79). 


\section{míDiA eCOti DiAno}

\section{PPGMC}

Verifica-se, portanto, que “a comunicação é a questão de maior relevância quando se fala de cultura organizacional” (IDEM, p. 87). A comunicação é fundamental porque é por seus instrumentos que há o compartilhamento necessário dos valores, bem como a preservação e o aprimoramento deles (VALSANI, 2008, p. 206) nas instituições e, como as organizações religiosas se valem justamente desses valores, intrínsecos em sua missão, para a existência e atuação é necessário lidar de maneira estratégica com a comunicação que perpassa todos os níveis de sua formação. O descuido, por menor que seja, pode levar a adoção de práticas e valores contrários a essência da instituição religiosa, o que enfraquecerá a sua existência.

É por meio da cultura que são realizados os discursos que constroem então a identidade das organizações, pois ela se constrói, se mantém ou se destrói a partir da produção dos discursos na mente de quem os recebe (IASBECK, 2009, p. 9):

A identidade organizacional é o que é considerado pela maioria dos empregados/voluntários como a essência da organização; o que faz a organização se distinguir de outras e o que é percebido como estável ao longo do tempo, ou seja, o que faz a ligação entre o presente e passado e, provavelmente, o futuro (ALMEIDA, 2008, p. 34).

O assessor de imprensa é o elo que media os discursos para que sejam coerentes com a cultura e também à identidade, pois são justamente os discursos organizacionais que formarão a imagem na mente dos públicos. Podendo ser então, coerentes ou não com a atividade da organização, fazendo jus a sua identidade ou prejudicando-a. O assessor sabe a importância da correta exposição e por isso atua diretamente para que os discursos sejam coerentes e uníssonos, evitando os problemas das distorções que "a assessoria de imprensa comumente trabalha para desfazer mal-entendidos, expurgando as leituras diversas daquela(s) intencionada(s) pela comunicação oficial” (IASBECK, 2009, p. 24).

Já a imagem da organização, aquilo que é percebido pelo receptor, pode sofrer desvios pela sua interpretação do discurso e por isso, esses canais precisam ser objetivos e coesos sobretudo nas instituições religiosas. A imagem chega ao indivíduo como 


\section{PPGMC}

DiAno

consequência de informações e interações por isso não basta apenas divulgar mais sim dialogar com os públicos. Com maiores e melhores interações a imagem, que é "o conjunto de significados pelo qual um objeto é reconhecido e que o indivíduo utiliza para descrevêlo, relembrá-lo e com ele se relacionar” (ALMEIDA, 2008, p. 38), tende a não sofrer distorções e pode convidar a sociedade a partilhar dos ideários das organizações, que são orientadas por suas identidades, valores, missões e visões (NASSAR, 2008, p. 247).

As distorções comunicativas afetam a credibilidade dos indivíduos e das organizações, tanto que "só há identidade quando a imagem convive harmoniosamente com as intenções estratégicas do discurso institucional” (IASBECK, 2009, p. 28). Esse exemplo é facilmente ilustrado no ambiente eclesial com as ambiguidades das denominações cristãs brasileiras, que se confrontam publicamente em uma guerra pelos fiéis, e das alas extremistas islâmicas que atuam com violência ao redor do mundo, quando os seus escritos sagrados defendem a tolerância e a paz.

Dentro de um ambiente onde a cultura serve como espelho e reflete a essência da organização, um processo que necessariamente envolve e produz conhecimento, é a comunicação que cria a cultura organizacional e fortalece a identidade (MARCHIORI, 2008, p. 85) e consequentemente transmite também uma imagem coerente com essa identidade. Sendo assim, o uso profissional da assessoria de imprensa pelas instituições religiosas ajudará na cultura, na identidade e na imagem e tende a levar à reflexão de todos esses itens; o que proporciona a aproximação da instituição com a comunidade, permitindo que sejam feitas as adaptações necessárias para que haja relevância no dia a dia do ambiente eclesial. Além disso, o uso de mecanismos profissionais da assessoria de imprensa permite a oportunidade para rever a coerência entre os princípios e os valores expressos na missão das instituições religiosas frente as suas atividades realizadas.

Não cabe a assessoria atuar isoladamente, uma vez que a comunicação integrada organizacional abrange outros aspectos como administrativos, eclesiais, relações públicas e por vezes o próprio marketing. Porém, ela é uma ferramenta estratégica importante que auxilia a reflexão e a atuação das instituições religiosas e tende a ser um forte instrumento para que elas revejam a própria cultura eclesial; muitas vezes fechada ao 


\section{míDiA \\ eC \\ DiAno}

\section{PPGMC}

diálogo e que pende para uma comunicação não participativa, tanto interna quando externamente.

\section{Mecanismos profissionais versus proselitismo}

As instituições religiosas como integrantes e representantes da sociedade acompanharam de maneira direta ou indireta as transformações socioculturais no decorrer dos anos. Em relação a comunicação, a União Cristã Brasileira de Comunicação Social (UCBC) em meados dos anos 80, propôs uma metodologia comunicativa diferente em relação a audiência, buscou nos estudos de Jesús Martín-Barbero a valorização da experiência, cultura e valores dos receptores principalmente na classe popular (GOMES, 1999, p. 160).

Com essa atitude, a UCBC demonstrou que as minorias, entre elas as religiosas, atuavam fortemente para expor a singularidade (BARBALHO, 2009, p. 29) e buscavam interagir com a comunidade de maneira mais transparente e eficaz.

Porém, o passar das décadas e a combinação religião-mídia fez os evangélicos despojarem os púlpitos e altares para dar lugar ao palco, em cujo espaço o culto se teatralizou e a religião se tornou um espetáculo (CAMPOS, 2002 p. 253). Essas modificações, vistas a partir do andar lado a lado com a mídia, "possibilitou a transformação organizacional das várias instituições religiosas que são produzidas e que passam a operar no mercado, trazendo reflexos significativos em seus discursos e práticas religiosas” (PATRIOTA, 2001, p. 95).

A fé virou mercado para muitas instituições religiosas que nas compras de horários televisivos, quase nobres, ou em outros meios de comunicação passaram a ter dificuldade em lembrar que não são empresas do segundo setor e que ao adotarem práticas antagônicas aos valores religiosos, mercantilizaram a religião e banalizaram os discursos que como canais até os públicos já não representam credibilidade ou condizem com a identidade outrora apresentada. 


\section{míDiA \\ eClosin DiAno}

\section{PPGMC}

Os padres e os pastores mudaram as suas apresentações e as interações tornaram-se espetacularizadas. Atualmente, os padres são cantores, motivadores e reconhecidos pelo seu lado pop, com ou sem a vestimenta sacerdotal; como é o caso do Padre Marcelo Rossi e do Padre Fábio de Melo, respectivamente. Já em relação aos líderes do protestantismo pode ser dito que

\footnotetext{
O pastor protestante que antes era um especialista muito próximo do doutor em letras, notável pelo saber exegético e pela comunicação oral em um sermão racional e longo, precisa agora dar espaço para um hábil comunicador, que sabe trabalhar bem em termos de marketing as necessidades e os desejos de seu auditório (CAMPOS, 2002, p. 255).
}

Seja a ala conservadora ou a vanguarda das instituições religiosas brasileiras elas se valem da modernização dos meios de comunicação para alcançar os seus públicos, com compras de horários em emissoras ou com a compra ou fundação de suas próprias emissoras. Porém, os discursos tendem ao proselitismo exacerbado que declara uma guerra pela conquista de fiéis. O televangelismo, por exemplo, apesar de ter um desempenho pouco satisfatório no seu principal propósito que é a conversão, guarda importantes consequências secundárias. Pois expande as fontes de formação e informação das igrejas.

Os programas de televisão e rádio chegam a ser tão importantes quanto os colégios, casas publicadoras ou estúdios cinematográficos. Representam na comunidade o status alcançado e a riqueza, por sua participação mais ativa no mercado. Além de criar um senso de comunidade ou comunhão entre os telespectadores e fiéis e promover a participação dos leigos no trabalho religioso da participação financeira ou divulgação (FONSECA, 2007, p. 141). Ao reduzir o espaço midiático na guerra por fiéis, a produção do conteúdo religioso diminui o compromisso maior de transformar a sociedade (JOSGRILBERG, 2007, p. 153) e distorce a atuação eclesial na comunidade, chegando ao ponto de afastar os seus públicos.

O grande pluralismo religioso brasileiro, com a diminuição do seu papel transformador, "cria a sua própria demanda, pelo marketing e usa os instrumentos midiáticos para os serviços religiosos na concorrência de fiéis” (PATRIOTA, 2001 p. 24). 


\section{míDiA \\ eCrosia DiAno}

\section{PPGMC}

Tanto o catolicismo quanto o protestantismo fazem o uso dos instrumentos midiáticos ao ponto que as novas religiões cristãs já nascem fundidas com a mídia, principalmente a tv e respondem naturalmente a esse bios midiáticos (BERGE, 2007, p. 29). Porém, esses usos midiáticos são realizados de maneira viciada que privilegiam as disputas denominacionais, a ponto de não utilizarem as demais ferramentas comunicativas, como a assessoria de imprensa ou as relações públicas.

Percebe-se que a atuação proselitista das instituições religiosas assume em determinados momentos o contorno de proselitismo agressivo que ataca outras religiões e por isso a exposição midiática não busca apenas construir uma imagem positiva perante a sociedade, passa a ser quase que exclusivamente uma defesa institucional (FONSECA, 2007, p. 139). Ou seja, ou invés de dialogar para os seus públicos e procurar atividades e adaptações relevantes, as instituições se isolam em discursos distorcidos e avançam pelos diferentes espaços em busca de um amparo que há muito, perdeu a relevância do seu poder transformador.

Por isso, os comunicadores que lidam com as instituições religiosas precisam de uma formação que passe pelo domínio dos objetos técnicos e estratégias comunicativas (JOSGRILBERG, 2007, p. 157) na intenção de apresentar os mecanismos profissionais disponíveis às instituições, que contribuirão para os ajustes na cultura e influenciará positivamente a identidade e consequentemente também a imagem.

Mesmo sendo uma ferramenta conhecida e utilizada durante décadas em nosso país, o cenário religioso midiático no Brasil demonstra que a assessoria de imprensa não tem tido a sua importância salientada e nem sequer, os seus recursos são aplicados de maneira profissional no âmbito eclesial.

A assessoria de imprensa permite uma maior atuação das instituições religiosas, de maneira profissional e não distorcida pelo proselitismo agressivo na guerra por fiéis. É por meio dela, que é possível apresentar a relevância transformadora religiosa, pois permite maior e melhor interação com a comunidade durante o processo de diálogo organizaçãomídia-comunidade. Deixar a assessoria de lado, demonstra que a relevância da organização eclesial já não é tão contundente e o discurso tende apenas ao campo dos ataques e das 


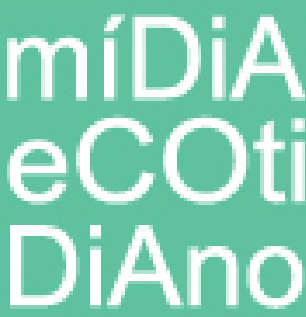

\section{PPGMC}

defesas proselitistas. Esquecendo-se assim, do poder de visibilidade e de diálogo que o serviço de assessoramento pode providenciar ou resgatar. Afinal, pela assessoria de imprensa é possível às instituições religiosas usarem os mecanismos profissionais e ressaltarem as parcerias entre os setores da sociedade, dialogar a respeito de projetos sociais e demais ações transformadoras no ambiente sociocultural. É a incorporação das ferramentas comunicacionais disponíveis na assessoria de imprensa que se torna um dos mecanismos facilitadores para ampliar o vínculo e a participação social das instituições religiosas através da mídia e não ficar atrelado apenas ao proselitismo.

O presente estudo permite a continuação da pesquisa com vistas às instituições religiosas que se valem da assessoria de imprensa, o que tende a gerar comparações de posicionamento com as que não utilizam os mecanismos profissionais da assessoria e pendem ao viés exclusivista da guerra proselitista por fiéis. Além de se ser possível conferir diferenciações do diálogo e da relevância da própria instituição com a comunidade a partir da ampliação ou do início do uso profissional da assessoria de imprensa.

\section{Referências}

ALMEIDA, Ana Luisa de Castro. A construção de sentidos sobre "quem somos e "como somos vistos”. In: MARCHIORI, Marlene. (Org.). Faces da cultura e da comunicação organizacional. São Caetano do Sul, SP: Difusora Editora, 2008.

ASHELY, Patricia Almeida (Coord.). Ética e responsabilidade social nos negócios. São Paulo, SP: Saraiva, 2005.

BARBALHO, Alexandre. Cidadania, Minorias e Mídia: ou algumas questões postas ao liberalismo. In: BARBALHO, Alexandre; PAIVA, Raquel (Org.). Comunicação e Cultura das Minorias. São Paulo, SP: 2005.

BERGE, Christa. Tensão entre os campos religioso e midiático. In: ENDO, Ana Claudia Braun.; GOBBI, Maria Cristina.; MELO, José Marques de. (Org.). Mídia e Religião na 


\section{míDiA \\ eC \\ DiAno}

\section{PPGMC}

Sociedade do Espetáculo. São Bernardo do Campo, SP: Universidade Metodista de São Paulo, 2007.

BUENO, Wilson da Costa. Comunicação Empresarial: teoria e pesquisa. Barueri, SP: Manole, 2003.

A comunicação como inteligência empresarial competitiva. In:

KUNSCH, Margarida M. Krohling (Org.). Comunicação Organizacional, vol.1: Histórico, fundamentos e processos. São Paulo: Saraiva, 2009.

CAMPOS, Leonildo Silveira. Comunicação Religiosa: dos modelos marxistas aos modelos neoliberais na análise do uso religioso dos meios de comunicação de massa no Brasil. In: GOBBI, Maria Cristina; KUNSCH, Waldemar Luiz; MELO, José Marque de. (Org.). Matrizes Comunicacionais Latino-Americanas: Marxismo e Cristianismo. São Bernardo do Campo, SP: Universidade Metodista de São Paulo, 2002.

DRUCKER, Peter F. Administração de organizações sem fins lucrativos: princípios e práticas. São Paulo: Cengage Learning, 2006.

DUARTE, Jorge e FARIA, Armando Medeiros de. Media-training: capacitando fontes e porta-vozes. In: DUARTE, Jorge. (Org.). Assessoria de Imprensa e Relacionamento com a Mídia: teoria e técnica. São Paulo: Atlas, 2011.

ENRÍQUEZ, Carlos Sotelo. Introducción a la comunicación institucional. Barcelona, Espanha: Ariel Comunicácion, 2001.

FENAJ, Federação Nacional dos Jornalistas. Manual de Assessoria de Comunicação. Brasília, DF: FENAJ, 2007. 
FERRARETTO, Luiz Artur e KOPPLIN, Elisa. Assessoria de imprensa: teoria e prática. Porto Alegre: Editora Sagra Luzzatto, 2001.

FONSECA, Alexandre Brasil. Cidadania e Justiça na formação de recursos humanos para a mídia. In: ENDO, Ana Claudia Braun.; GOBBI, Maria Cristina.; MELO, José Marques de. (Org.). Mídia e Religião na Sociedade do Espetáculo. São Bernardo do Campo, SP: Universidade Metodista de São Paulo, 2007.

GOMES, Pedro Gilberto. Comunicação, Cultura e Mediações: Jesús Martín-Barbero e o Brasil. In: DIAS, Paulo da Rocha e MELO, José Marque de. (Org.). Comunicação, Cultura, Mediações: o percurso intelectual de Jesús Martín-Barbero. São Bernardo do Campo, SP: Universidade Metodista de São Paulo, 1999.

IASBECK, Luis Carlos Assis. Identidade organizacional e a construção dos discursos institucionais. In: KUNSCH, Margarida M. Krohling (Org.). Comunicação Organizacional. vol.2: Linguagem, gestão e perspectivas. São Paulo: Saraiva, 2009.

JOSGRILBERG, Fabio B. Admirable commercium: Religião e comunicação no período técnico-científico-informacional. In: ENDO, Ana Claudia Braun.; GOBBI, Maria Cristina.; MELO, José Marques de. (Org.). Mídia e Religião na Sociedade do Espetáculo. São Bernardo do Campo, SP: Universidade Metodista de São Paulo, 2007.

KUNSCH, Waldemar Luiz. Gênese e desenvolvimento do campo profissional e acadêmico das relações públicas no Brasil. In: KUNSCH, Margarida M. Krohling (Org.). Relações Públicas: história, teorias e estratégias nas organizações contemporâneas. São Paulo: Saraiva, 2009.

MARCHIORI, Marlene. Cultura e comunicação organizacional: uma perspectiva abrangente e inovadora na proposta de inter-relacionamento organizacional. In: 
MARCHIORI, Marlene. (Org.). Faces da cultura e da comunicação organizacional. São Caetano do Sul, SP: Difusora Editora, 2008.

NASSAR, Paulo. A comunicação como valor estratégico. In: MARCHIORI, Marlene. (Org.). Faces da cultura e da comunicação organizacional. São Caetano do Sul, SP: Difusora Editora, 2008.

OLIVEIRA, Maria José da Costa. Comunicação pública e as estratégias de relações públicas nas alianças intersetoriais. In: KUNSCH, Margarida M. Krohling (Org.). Relações Públicas: história, teorias e estratégias nas organizações contemporâneas. São Paulo: Saraiva, 2009.

PATRIOTA, Karla Regina Macena Pereira. Nós temos o que você precisa: uma reflexão sobre a religiosidade midiática na sociedade de consumo. In: ENDO, Ana Claudia Braun.; GOBBI, Maria Cristina.; MELO, José Marques de. (Org.). Mídia e Religião na Sociedade do Espetáculo. São Bernardo do Campo, SP: Universidade Metodista de São Paulo, 2007.

PINHO, José Benedito. Propaganda institucional: usos e funções da propaganda em relações públicas. São Paulo: Summus, 1990.

SALVATORE, Vilu. A Racionalidade do terceiro setor. In: VOLTOLINI, Ricardo. (Org.). Terceiro Setor: planejamento \& gestão. São Paulo: Editora Senac, 2004.

VALSANI, Flávio. Comunicação institucional. In: MARCHIORI, Marlene. (Org.). Faces da cultura e da comunicação organizacional. São Caetano do Sul, SP: Difusora Editora, 2008. 


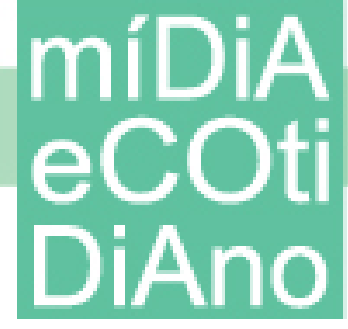

\section{PPGMC}

VOLTOLINI, Ricardo. Marketing, uma ferramenta útil para o terceiro setor. In: VOLTOLINI, Ricardo. (Org.). Terceiro Setor: planejamento \& gestão. São Paulo: Editora Senac, 2004. 